dry organic matter with algae than with customary field-crops which cover the ground and form an almost uninterrupted photosynthetic loyer only during a short part of the year.

A great effort is directed towards the elucidation of the main factors in algal growth and reproduction, for example, the effect of light-intensity, temperature; different nutrient solutions, density of cell-suspension, intermittent light, etc. At the same time, the dimensions of the experiments are steadily increased, from test-tubes and flasks to large bottles and so on, eventually to pilot plants.

So far no alga has proved superior to Chlorella pyrenoidosa in productivity; but it seems possible that other: properties may in future play a part: among others, easier harvesting, hardiness against high temperatures as caused by insolation, or against chemical admixtures to the ordinary agricultural fertilizers which will have to replace the pure chemicals now in use.

The contributions by various authors are of unequal value. Those who believe that pure cultures are not indispensable for achieving heavy yields continuously are in the minority but not yet defeated, although their achievements are not impressive. Some new discovery may alter that. There is a great deal of information in this volume which will stimulate research in many ways. $\quad$ E. G. Pringsheim

\section{PLANT GENERA}

\section{Plant Genera}

Their Nature and Definition. A Symposium by G. H. M. Lawrence, I. W. Bailey, Arthur J. Eames, Reed C. Rollins, Marion S. Cove and Herbert L. Mason. With an introductory essay on Generic Synopses and Modern Taxonomy by Theodor Just. (Chronica Botanica, Vol. 14, No. 3.) Pp. 91-160. (Waltham, Mass.: The Chronica Botanica Co.; London: William Dawson and Sons, Ltd., 1953.) 2 dollars.

THE genus occupies an impartant place in the 1 hierarchy of taxa. Historically, it was recog. nized as a reasonably clear concept before the species or the family. Nomenclaturally, it is the basis for the manufacture of most family names and forms the specific name in combination with the specific epithet. Phytogeographically, the ranges of genera provide data (and problems) that are often of greater significance than those yielded by the ranges of species or families. There are thus valid reasons for periodically reviewing the generic concept.

The symposium on plant genera to which notice is given here was apparently largely initiated by Dr. F. Verdoorn, the editor of "Chronica Botanica", who contributes $a$ foreword in which he pleads for " $a$ " national or international scheme which will result in the preparation of a complete, somewhat uniform, series of generio floras".

In an introductory essay Theodor Just notes that, we now recognize the need for different kinds of genera and, while supporting the scheme for generic floras, shows that these must be prepared by longterm team work. G. H. M. Lawrence refers to various taxonomic "trouble-spots" and declares his belief "that the answers will not be found, until we taxonomists function as synthesizers, until we focus on each problem all the pertinent data to be had from related fields of botanical effort". This emphasis on what has been called synthetic taxonomy is increased by other contributors, as by I. W. Bailey in an anatomical approach, A. J. Eames for floral anatomy, R. C. Rollins with regard to cytogenetics, M. S. Cave for cytology and embryology, and H. L. Mason in dealing with the role of plant geography in taxonomy.

As many of the writers clearly point out, no one set of criteria, no group of characters from a restricted field can alone result in a widely satisfactory delimitation of genera (or other taxa). The difficulties, practical and theoretical, of utilizing diverse "characters' in taxonomy are not to be gainsaid. Much modern work has shown that they can be overcome and that the results can be expressed, at least to a very large extent, within the existing framework of taxonomy. Subsidiary schemes are often useful if only temporarily and within narrow limits, but no general replacement of the species-genus-family hierarchy has yet been proposed and tested to meet with wide acceptance.

The idea of preparing "generic floras" or "genera plantarum" to include all cryptogams and phanerogams needs careful consideration. Genera are composed of species and, concretely, species are composed of individuals. It may be argued that delimitation of genera should succeed, not precede, the study of the species involved. In other words, if the modern methods of synthetic taxonomy be accepted, monographic work is essential before the genera can be satisfactorily determined. There is a danger in deciding on generic criteria and generic limits without fully examining every species and ultimately every available specimen and all data. It is true that a genus can often be adequately determined without settling every specific and intraspecific nomenclatural problem but not without fully. studying the 'characters' of, and within, all the species and specimens available. The question then arises: "Is it not worth while spending the extra time and properly monographing the group ?"

W. B. TURRILI

\section{CHEMISTRY OF TISSUE SECTIONS}

\section{Histochemistry}

Theoretical and Applied. By Dr. A. G. Everson Pearse. Pp. viii $+530+35$ plates. (London: J. and A. Churchill, Ltd., 1953.) 60s. net.

A $S$ Dr. Pearse says in his preface: "HistoA chemistry can transform the descriptive sciences of biology into dynamic and functional sciences". His book "is an endeavour to compass the whole of histochemistry as applied to tissue sections".

The book opens with a short chapter on the history of histochemistry, followed by a discussion of fixation and freeze drying. Then proteins, nucleic acids, carbohydrates, lipids, carbonyl compounds, various enzymes, pigments and inorganic constituents are treated in succession, and to conclude there are brief chapters on physical methods and appendixes, compiled in cookery-book style, on histochemical procedures.

To write a text-book on a subject which is still in its early stages of development is to offer many hostages to fortune. What fortune will do with them remains to be seen. In the meantime this book constitutes intelligent comment on the present position in histochemistry, which will be of interest 